\title{
Responding to Literature Texts through Films in English and the L1 within a Multiliteracies Pedagogy
}

\author{
Shakina Rajendram (Corresponding author) \\ Department of Curriculum, Teaching and Learning \\ Ontario Institute for Studies in Education, University of Toronto \\ 252 Bloor St W, Toronto M5S 1V6, Canada \\ E-mail: shakina.rajendram@mail.utoronto.ca \\ Mallika V. Govindarajoo \\ Department of Language and Humanities Education \\ Faculty of Educational Studies, University Putra Malaysia \\ 43400 UPM Serdang, Selangor, Malaysia \\ E-mail: mallika.vasugi@gmail.com
}

\author{
Received: 08-09-2015 \\ Accepted: 06-12-2015 \\ Advance Access Published: December 2015 \\ Published: 01-03-2016 \\ doi:10.7575/aiac.ijalel.v.5n.2p.56 \\ URL: http://dx.doi.org/10.7575/aiac.ijalel.v.5n.2p.56
}

\begin{abstract}
This article presents the results of a study exploring the aesthetic and critical responses of English as a Second Language (ESL) learners when engaging in the multimodal design of literature texts through films in English and their first language (L1). Participants consisted of 25 culturally and linguistically heterogeneous first-year undergraduate students in a Literature in English Language Teaching program in a Malaysian public university. The participants engaged in a multi-modal design of the novel Step by Wicked Step by Anne Fine in three phases over a period of eight weeks based on the four components of the multiliteracies approach: situated practice, overt instruction, critical framing, and transformed practice. The transformed practice component of this approach involved students making and presenting short films both in English and in a local Malaysian language or dialect. Data for the study came from six focal participants' journal reflections throughout the project and semi-structured interviews with them. The findings showed that the multimodal design of texts through films in the L1 increased personal meaningfulness and intercultural understanding. It also allowed learners to function as language experts, take liberties with the text, and look beyond the text for inspiration from dramas and movies.
\end{abstract}

Keywords: Multiliteracies, Multimodal, Literature, Reader Response, L1, ESL

\section{Introduction}

\subsection{Background}

To arrest a decline in English language proficiency among Malaysian students, one of the moves by the Malaysian Ministry of Education (MOE) was to introduce literature texts as part of the English language curriculum in schools. The objectives of this move as outlined by the MOE include enhancing students' proficiency in English as well as contributing to personal development and character building. Desired syllabus outcomes also include empowering students to give personal response to texts and to show awareness of how language is used to achieve a particular purpose. However, studies revealed that Malaysian secondary school students showed little interest towards the prescribed literature texts due to irrelevance of themes, mismatch of students' language competence and cultural distance (Vethamani 2004). Another reason for students' lack of enthusiasm was the instructional methodology employed by teachers in the ESL classroom (Vethamani, 2002). The majority of teachers in fact admitted to a lack of adequate knowledge of literature teaching methodologies and indicated that they would use the English examination paper as a benchmark of what to teach (Subramaniam, Hamdan and Koo, 2003). To address the lack of relevance and interest among students the MOE introduced a new set of literary texts including novels to be used in the ESL classroom in 2010.

In 2011, the Malaysian Ministry of Education launched the revised English Language and English Literature curricula to counter the problem of exam-oriented teaching in Malaysian classrooms (Ministry of Education Malaysia, 2012). The new curricula aimed to shift the focus of education to more independent, project-based, problem-based, and inquirybased learning. The revised English Language and English Literature curricula guidebooks provided unit and lesson plans based on elements from the multiliteracies pedagogy, which is structured in four components (New London Group, 2000):

(i) Situated Practice - providing meaningful and authentic experiences for students to participate in their own learning by building on their lived experiences. 
(ii) Overt Instruction - providing active intervention and scaffolding to make concepts explicit for students and help them gain conscious control of their learning.

(iii) Critical Framing - helping students to analyze what they are learning from a critical perspective in relation to the "historical, social, cultural, political, ideological, and value-centered relations of particular systems of knowledge and social practice" (New London Group, 2000, p. 21).

(iv) Transformed Practice - helping students to apply what they have learned in new contexts by transforming existing meanings to design new meanings (Mills, 2006).

Within the multiliteracies framework, students draw on available designs (for example, the linguistic information in a book) to design (make meaning and create) a redesigned (transformed) multimodal text (Kalantzis \& Cope, 2005). Multimodal texts are texts that combine two or more communication modes (e.g., print, image, music, film, etc.) or semiotic systems (e.g. linguistic, visual, audio, gestural, spatial) to enhance or transform the meaning of a text (Anstey \& Bull, 2010).

\subsection{Problem Statement}

The purpose of the changes that were made to the Malaysian English Language and English Literature curricula was so that teachers would move away from passive, teacher-oriented content delivery, and focus instead on fostering creativity and developing learners' competencies in higher order, critical thinking skills (Chapman, 2010). However, despite these innovations, studies have found that the pedagogical practices in most Malaysian schools are still characterized by "conventional approaches to grammar drills, classroom confined settings, textbook-centred methods, teacher as the primary source of information, students as passive learners, excessive pressure to pass exams and an emphasis on uniformity" (Kaur, Ganapathy and Sidhu, 2012, p. 119). The activities carried out in English literature lessons are very much teacher-centred in the sense that learners are passive receivers rather than active participants and co-constructors of meaning. Even when teachers conduct multimodal design activities (e.g., students performing a drama based on a story), learners are often guided into pre-scripted responses which displayed more surface-level content understanding of the texts rather than critical thinking about their social, political and cultural issues and implications. Making similar observations, Lankshear, Snyder and Green (2000) refer to teachers' use of new technologies to fit their traditional and familiar approaches to literacy teaching and learning - for example, children typing up a story on the computer rather than rewriting their final draft - as the "old wine in new bottles" or "digital makeover" syndrome (p. 102, as cited in Neville, 2010, p. 239). Furthermore, the English-only policy enforced by most Malaysian teachers in their classrooms make it difficult for students to express not only their critical responses to texts, but also the type of genuine, personal aesthetic response to texts that Rosenblatt (2005) advocates in her transactional reader response theory.

\subsection{Purpose of the Study}

According to Rosenblatt (2005), the literary work is a particular and personal event to the reader - "the electric current of his mind and personality lighting up the pattern of symbols on the printed page" (p. 63). Rosenblatt explains that when teaching literature, teachers should be concerned with the particular and personal ways that students can infuse their own meaning into the texts, and that "the atmosphere in the classroom...must permit a personal response to what is read." (p. 64). According to Rosenblatt (1978) also, the wealth of experiences, emotions and knowledge that readers bring to literature can be a means of promoting aesthetic as well as critical responses to literature. However, when teachers restrict students' design of texts to the language they are learning instead of the language of their homes and hearts (Weiyun He, 2010), their aesthetic and critical responses may be limited by their proficiency in the target language.

A number of studies have demonstrated the value of drawing on students' cultural and linguistic resources, particularly their L1, through multiliteracies and multimodal projects. For example, Ntelioglou, Fannin, Montanera and Cummins (2014) found that giving students the opportunity to create multimodal texts through multiple languages allowed them to make their texts and narratives their own, fostered learner autonomy, identity investment and literacy engagement. Similarly, Giampapa (2010) found that when the teacher in her study used a multiliteracies pedagogy that built on the linguistic and cultural resources of students, they took more ownership over their learning, and responded more creatively and critically to texts in their writing. However, an area with a limited research base pertains to the use of multimodal response to and design of literature texts (e.g. novels, short stories) in learners' L1. Although current research on reader response to literature has expanded to recognize the "multifaceted and synergistic nature of reader, textual and contextual factors that shape student response in classrooms" (Pantaleo, 2013, p. 125), the influence of learners' L1 on their multimodal response to literature remains an area in need of further research. In light of this, the purpose of this study was to explore the following research question: How does engaging in the multimodal design of literature texts through films in learners' L1 instead of English make a difference in their aesthetic and critical responses?

\section{Research Design and Methods}

\subsection{Participants and Setting}

This study was conducted in a Malaysian public university situated in a suburban location. The participants consisted of 25 first-year undergraduate students in a Literature in English Language Teaching program. These 25 participants were made up of 10 male and 15 female students between the ages of 18-19. The participants were all born and raised in 
Malaysia, but are culturally and linguistically heterogeneous. All of the participants are multilingual, with most of them speaking at least two languages. These languages include English, Malay, Tamil, Hindi, Cantonese, Mandarin, and a few Malaysian dialects. All of the participants had studied English as a subject at both the primary and secondary school level prior to beginning their undergraduate study, and their English proficiency levels ranged from intermediate to advanced. Six of the participants were chosen as focal participants for the study on a voluntary basis - Jacintha, Alan, Ryan, Harprit, Mira and Azham (pseudonyms have been used to protect the identity of the participants).

\subsection{Teaching Innovation}

As part of their literature module, the students were required to read and respond to the novel Step by Wicked Step by Anne Fine. This novel, written in an autobiographical style, tells the story of a group of schoolchildren, Claudia, Colin, Ralph, Pixie and Robbo, who spend the night in a big, old house, Harwick Hall, while on a field trip (Fine, 1997). After they find the diary of Richard Harwick who wrote about his experiences with his stepfather, the five children decide to share their own experiences with stepparents and stepsiblings. The participants engaged in a multi-modal design of the novel Step by Wicked Step in three phases over a period of 8 weeks. In Phase 1 which took place over 3 weeks, they engaged in critical literary practices through the first three components of the multiliteracies approach:

1. Situated Practice: Students talked about their family backgrounds. They shared with each other their experiences and thoughts about issues such as parental and sibling conflicts. They also began to look at the similarities and differences between their own perceptions about the family structure.

2. Overt Instruction: As students read through the novel, they received overt instruction to help them focus on the important features of the novel. Through guided discussions and scaffolded activities, students explored the plot, characters and themes of the novel. Students also received instruction on simple film-making techniques (planning a storyboard, filming using digital cameras or smart phones, putting music and subtitles to the film, etc.)

3. Critical Framing: Students analyzed and discussed the implicit social and cultural themes in the novel. They made connections between these themes and the current family-related issues and practices in their own community and in other societies. They looked at the language used in the novel and interpreted how the language interacted with the social and cultural contexts of the novel to complement or alter the story. Students were also challenged to examine their own beliefs and those of the characters in the novel.

In Phase 2 of the study which took 4 weeks, the participants engaged in the fourth component of the multiliteracies pedagogy - Transformed Practice. They were given the task of choosing one of the characters in the novel, and making two short films (5-10 minutes) based on one scene in the book involving that character. In groups of 5, students made one film in English, and another in their L1 or in a common Malaysian dialect spoken by the members of the group. Through this project, participants transformed what they learned about the novel in Phase 1 into their redesigned multimodal text which combined the following five semiotic systems (Anstey \& Bull, 2010):

Linguistic (the vocabulary, structure and grammar of the two languages)

Visual (combining still and moving images to create the films)

(iii) Auditory (using music and sound effects to enhance the stories)

(iv) Gestural (the body language, facial expression and movement in the acting)

(v) Spatial (the use of environmental and architectural space and positioning)

During Phase 3, students presented their short films to the rest of the class over one week. They also shared their collaborative and individual reflections on the novel and the film-making project. Throughout Phase 2 and Phase 3 of the study, participants kept journals in which they were free to write about any aspect of the novel or the activities they participated in.

\subsection{Data Collection and Analysis}

This research used a qualitative research design with descriptive qualitative data analysis methods. Six of the students were chosen as the focal participants for the study, and their journals, along with the short films, were used as the main data for this research. To answer the research question, the researchers analyzed the focal participants' films, journal entries and interview responses to see if there were differences in students' aesthetic and critical responses to the original text/available design (novel), the design (film-making process) or the redesigned texts (films) in their home language as compared to in English. The researchers organized these findings according to the themes that emerged in the data.

For the purpose of this study, the researchers defined aesthetic responses as the personal, affectively based experiencing of, engagement with, and response to literature texts (Soter, Wilkinson, Connors, Murphy \& Shen, 2010; Pantaleo, 2013). Learners' critical responses were identified based on the taxonomy of critical reading responses proposed by Sommers, Androne, Wahlrab and Polacheck (2006; see Table 1). This framework was formulated based on a study of the critical literary reading responses demonstrated by first-year undergraduate students in an introductory literature course. Sommers et al.'s (2013) framework (see Table 1) characterizes an incremental building of responses to literature. 


\begin{tabular}{|c|c|}
\hline Initial Responses to a Text & $\begin{array}{ll}\text { - } & \text { Forming emotional and/or abstract responses } \\
\text { - } & \text { Becoming immersed in a plot or character } \\
\text { - } & \text { Making personal judgments } \\
\text { - } & \text { Scanning text } \\
\text { - } & \text { Resisting interpretation } \\
\text { - } & \text { Decoding literal meanings of words } \\
\text { - } & \text { Verbalizing confusion } \\
\text { - } & \text { Asking factual questions }\end{array}$ \\
\hline Intratextual Responses to a Text & $\begin{array}{l}\text { - } \text { Constructing the text } \\
\text { - } \text { Citing text } \\
\text { - } \text { Recognizing textual moves } \\
\text { - } \text { Judging reflectively } \\
\text { - } \quad \text { Developing interpretive authority/exercising agency }\end{array}$ \\
\hline Extra-Textual Responses to a Text & 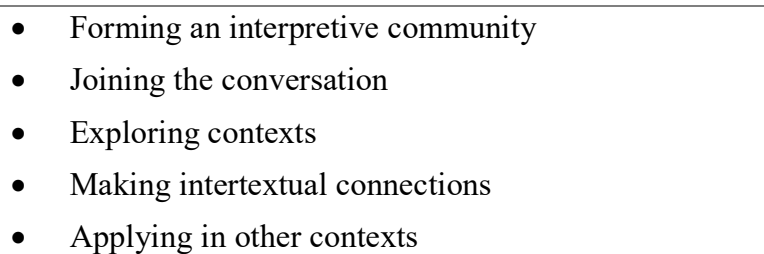 \\
\hline
\end{tabular}

The emerging themes from the films and journal entries were corroborated by semi-structured interviews conducted with the focal participants after Phase 3 had ended. The corresponding author conducted the interviews with the participants in English, and the transcripts of the interviews were analyzed qualitatively to uncover the themes that corresponded with the findings from the participants' journals and films. Some of the questions in the interview included: What part of the film-making process did you enjoy the most? Were there any parts of the film-making process that you did not enjoy? Did your experience making a film in English differ from your experience making a film in your own language, and how so? Which of the two films did you feel a more personal connection with?

\subsection{Ethical Considerations}

The researchers obtained permission from the class instructor and university administrators prior to conducting this study. As the film-making project was a compulsory part of the literature module of their program, all 25 of the students were required to participate in Phases 1-3 of the study. However, the interviews with the six focal participants were voluntary. The students who chose to participate in the interviews were given information and consent letters with details about the purpose of the study prior to the interview. They were also informed that they would not be penalized in any way or lose course credits or marks if they chose to withdraw from the interview at any point. Participant anonymity was maintained in the reporting of this study through the use of pseudonyms.

\section{Results and Discussion}

In the qualitative analysis of the films, participants' journal entries and interview responses, the researchers were able to identify five key emerging themes that characterized the differences between students' experiences making the films in English as compared to in their L1.

\subsection{Students as Language Experts}

In the first part of Phase 2 where students had to make a film in English, there was some resistance to the project by the students. Several of the focal participants expressed feelings of tension, particularly about working in groups. Jacintha, in one of her journal reflections, described the initial conflicts that arose within her group.

"On 7th of April we were informed that we should produce a video on the chapters in Step by Wicked Step novel as a group assignment. We were quite reluctant at first, because we are well aware of the tense in producing a video....There were misunderstandings between my friends. It made me quite disappointed and incensed because they did not realise the essence of working in groups unlike me and the other groupmates." -Jacintha (Journal)

However, as the groups moved into the process of making the films in their L1, many of the students began to step up as the "language experts" in their groups to assist their friends in different aspects of the design. For example, Alan, whose group was making a film in Tamil based on Robbo's story, initially recorded in his journal the difficulties he was encountering with translating the story into Tamil and creating English subtitles for it.

"HEADACHE! The process of editing the video was really complicated because there were so many things that need to be done. We encountered troubles with the subtitle because Azham and I could not insert the English subtitles for the Tamil video by ourselves as we do not understand the language very well..." -Alan (Journal) 
However, these problems were resolved when his group members who were more proficient in Tamil offered to take charge of writing the Tamil script.

"We needed our group members' help to really sit down and translate them so that the meaning of the speech would still be intact... Prema, Harini and Nisha helped to prepare the Tamil dialogue for the scenes which some of us are acting in." -Alan (Journal)

This collaborative effort between the group members seemed to increase group cohesion and alleviate the tensions felt by the participants at the beginning of the project. In his interview, Alan explained that with the help of the "Tamil experts" in the group, the project became a lot easier, and overall it was a "truly interesting and enjoyable experience."

\subsection{Taking Liberties with the Text}

In students' design of the novel in English, the students maintained a fairly rigid interpretation of the text. In the scripts they wrote for the English-language films, they used the lines and dialogues from the novel without making many changes in terms of the vocabulary, syntax, and level of formality. However, the researchers observed that in the design of the novel in students' L1, students took more liberties with the text and made both linguistic and extralinguistic changes to it. For example, Ryan had the task of writing the scripts for both the English and Cantonese versions of Pixie's story. His journal entries as well as the finished films suggested that when he wrote the script in English, his main focus was on maintaining the originality of the storyline and text.

"Writing a script is not an easy job especially if the script is based on a book or a novel since one has to keep the originality so that the storyline will not disperse from the actual plot." -Ryan (Journal)

However, when he wrote the script in Cantonese, Ryan explained that he had to use more of his creativity and imagination in order to "Malaysianize" the text. This also involved thinking critically about what aspects of the text he would need to change.

"I used my imagination while writing the script in terms of visualizing the settings and the suitable people to play the roles." -Ryan (Journal)

"When I wrote the script for Pixie's story in Cantonese, I was very excited because I could make it sound like a Malaysian story. But I had to think very hard... and I had to think critically about what changes to make... so that my story will still be creative but believable." -Ryan (Interview)

Jacintha, who also took on the role of scriptwriter for her group, exercised agency in making her own authorial choices in terms of the complexity of the language she used in the script.

"As I was the scriptwriter for Tamil video, I made a lot of simplifications spontaneously to make my friends able to pronounce it clearly." -Jacintha (Journal)

In her interview, she explained that she also made changes to the plot and the style of the language to suit the sociocultural setting of the redesigned text (a Tamil film which was set in a suburban Indian neighbourhood). Just like Ryan's group, Jacintha's group also made changes to their story that were apparent not just in the linguistic style of the script, but also in the characters, clothes, and props that they used in their films.

\subsection{Looking Outside the Text: Inspiration from Dramas and Movies}

Harprit, who had to play the role of Robbo's strict stepfather, Roy, recorded some of the difficulties he faced playing this character in his journal. These difficulties alluded to the differences between the concept of family in his culture and in the Western culture which the novel was framed within.

"I played the role as Roy in the story and had to act out the characteristics of a firm stepfather that did not get

along with the stepdaughter. It was difficult for me to act as Roy because I have no experience with stepparents and I don't know how a stepfather is supposed to be in Robbo's culture." -Harprit (Journal)

Surprisingly, the tone of Harprit's journal entries began to change when he got to the design in his L1. He managed to counter the problems he had initially faced by looking outside the novel and getting inspiration and guidance from Tamil television dramas and movies.

"I had no problem with the character because I have been studying those types of characters from local TV series and movies, especially Tamil dramas." -Harprit (Journal)

Although at first he was worried about his Tamil pronunciation, Harprit became more confident about his language as well as his acting after having watched many Tamil dramas and movies. In his interview, Harprit told the researchers that he had a lot of fun playing the part of Roy in Tamil, more so than in the English film.

"I enjoyed acting in Robbo's story in English. But I must admit that I had more fun speaking the dialogues in Tamil and my group members said that my pronunciation was almost natural... Yes, we had so much fun acting in Tamil and had to control our laughter so that we would appear perfectly for the characters that we were portraying." -Harprit (Journal)

\subsection{Personal Meaningfulness}

Mira, who played Claudia first in the English and then in Kedahan Malay (a Malay dialect), displayed quite a strong emotional reaction of disappointment about her portrayal of Claudia in the English film. She felt that her acting had not been natural and that her group should have put in more effort into perfecting the film. 
"After we watched all the videos... I felt quite dissatisfied with our first video and had a second thought that we should have put extra efforts and time to create the best. In my personal view, I felt that that I should have been more natural to act as Claudia." -Mira (Journal)

When asked to elaborate on her emotional reactions towards the design of the text in English, Mira explained it by comparing that experience with the process of designing the text in the Kedahan Malay version.

"There are so many huge differences in making both the videos. I personally felt that making the video in Kedahan Malay is more fun and meaningful to me. Seriously, filming the video was so much fun. This is very different to filming the English version. We had already memorized the script beforehand and just acted accordingly. The filming for English version took about three days while Kedahan version took us just half a day." -Mira (Interview)

Mira's emotional reaction towards the film-making process in Kedahan Malay, which stood in contrast to her reaction towards the English version, seemed to be related to how personally meaningful she perceived the design experience to be. Mira comes from Kedah herself (where Kedahan Malay originated), so she felt that Claudia's story was more personally meaningful and relatable to her when it was transformed into her home language, and that she didn't have to "try so hard" to play the role naturally. For Alan too, the design of the novel in his home language felt more personal to him and enabled him to identify with the characters better.

"This film project made me realize that the novel becomes so much relevant and personal to me. I can relate to what the characters are feeling especially when I get to immerse myself in one of the character. This is a very interesting novel because it deals with family problems and I am sure, many of us are experiencing this. Our students can definitely relate to the characters because many of us are not that fortunate with a happy family." Alan (Journal)

While watching the films made by all the students in their L1, the researchers made an interesting observation that the students used words in their L1 that were more emotionally loaded than their English counterparts. This could also point to the enhanced personal meaningfulness of the story, and the stronger emotional reactions it stirred when translated into students' L1.

\subsection{Intercultural Understanding}

Azham, for whom Tamil was not a home language, stated that learning Tamil for this project helped him to understand and appreciate his Tamil-speaking Malaysian Indian friends better. Importantly, he wanted his Indian friends to know that he valued their culture and their language.

"I understood other cultures better after finishing this video project. It is very interesting having the chance to learn to speak Tamil, and having been positively accepted by the viewers. I enjoyed speaking in Tamil because I have a lot of Indian friends and I enjoy befriending them. One of the purposes of me wanting to film the video in Tamil was that, I want to "give back" to my Indian friends for being good to me all these while. I want them to know that I am interested in their culture, especially the language and I want the viewers to feel the same way too." -Azham (Journal)

Azham's response is incredibly significant considering the fact that although he was a member of the dominant ethnic group in Malaysia, he willingly learned the language of the minority ethnic group so that he could affirm their culture, language and identity. The researchers feels that this is a reflection of one of the key strengths of this project - giving learners the opportunity to use their L1 in their multimodal design of the novel did not just create positive aesthetic responses; it also helped learners think critically about issues related to the status of the languages and their speakers in society.

\section{Conclusions and Implications}

Based on the findings of this study, the researchers conclude that engaging in the multimodal design of literature texts through films in learners' L1 instead of English made significant differences in their aesthetic and critical responses. Although some of the participants initially expressed frustration and anxiety towards the project, their aesthetic responses became more positive as they engaged in the design of the text through films in their home language. As they explored the broader sociocultural context of the redesigned text, they also displayed more of Sommers' et al. (2006)'s critical responses to the text such as exercising interpretive authority and agency, making authorial choices, and forming an interpretive community with their group members. The results of this research corroborate the findings of previous studies which have also shown that allowing learners to create multimodal texts in their own languages and cultures lets them take more ownership over their learning by becoming the experts and making the texts their own (Ntelioglou et al., 2014; Giampapa, 2010). Although the researchers were not able to investigate suggestions that the process of designing these multimodal texts enables learners to reconstruct and renegotiate their identities (Ntelioglou et al., 2014; New London Group, 2000), the themes that emerged from the study imply that in the process of creating the films both in English and in their L1, the learners did undergo a transformation in certain aspects of their identity. For example, Harprit grew more confident about his linguistic and acting abilities after having participated in the project. The concept of identity reconstruction and renegotiation through the design of multimodal texts in learners' L1 would be an interesting area for future research.

The results of this study support the use of multiliteracies-based pedagogical practices which value students' preferred mode of learning (Tan \& McWilliam, 2009) and the linguistic and cultural diversity they bring to the classroom. Thus, 
teachers should create learning environments that engage students in a wide range of creative and cognitively challenging literacy practices that combine text-based and multimedia forms of meaning making using both the target language and learners' L1 (Giampapa, 2010; New London Group, 2000). This is particularly important in the teaching of literature. Cai (2008) reminds us that it is only by bridging aesthetic response and critical reading that teachers can promote reflection and transformation in their literature readers (p. 218). The findings of this study have shown us the important role that learners' L1 play in building this bridge. The L1 can help students express their identification with personal aspects of the texts in a more reflective and transformative way.

It is also important for teachers to use multimodal reader response and design activities that allow their students to bring their own sociocultural knowledge, experiences and critical interpretations to texts. A study by Govindarajoo and Mukundan (2013) showed that students strive to identify and relate with parts of the texts that parallel familiar situations in their lives. The difficulties that Harprit faced in trying to understand the concept of stepparents in a different culture suggest the importance of literature-based lessons that help students to connect unfamiliar parts of a text to the familiar parts of their lives. In conclusion, the multimodal design of literature texts through films both in the target language and in the L1 is a valuable activity for teachers to explore in their classrooms because it can help students engage more directly and make stronger connections with the texts, as evidenced in Azham's words.

"This film project definitely helped me understand the novel better. Acting in the film project helped us understand the characters and their characteristics in depth. We managed to put ourselves in their shoes and we figured out why some characters behaved in different ways. This was a very interesting learning process because we understood the novel not by merely reading it, but by being actively involved in the project." Azham (Journal)

As it was beyond the scope of this research to investigate learners' aesthetic and critical literary responses during the situated practice, overt instruction, and critical framing components of this multiliteracies project, these are potential areas for future research. Another recommendation for future study is to explore the literature responses of students using other modes of representation, and through different local languages and dialects.

\section{Acknowledgements}

The authors would like to express their gratitude to the journal editor and reviewers, as well as the participants who made this research possible. The authors would also like to extend their special thanks to Dr. Shelley Stagg Peterson from the Ontario Institute for Studies in Education for her guidance and support in the writing of this paper.

\section{References}

Anstey, M., \& Bull, G. (2010). Helping teachers to explore multimodal texts. Curriculum \& Leadership Journal, 8(16). Retrieved from http://www.curriculum.edu.au/leader/helping_teachers_to_explore_multimodal_texts,31522.html.

Cai, M. (2008). Transactional theory and the study of multicultural literature. Language Arts, 85(3), 212-220.

Chapman, K. (2010, December 19). Change is due. The Star Online. Retrieved from http://www.thestar.com.my/Story/?file=\%2F2010\%2F12\%2F19\%2Feducation $\% 2$ F5889535\&sec=education

Cope, B., \& Kalantzis, M. (2009). "Multiliteracies": New literacies, new learning. Pedagogies: An International Journal, 4, 164-195.

Fine, A. (1997). Step by wicked step. New York: Yearling.

Giampapa, F. (2010). Multiliteracies, pedagogy and identities: Teacher and student voices from a Toronto elementary school. Canadian Journal of Education, 33(2), 407-431.

Govindarajoo, M. V., \& Mukundan, J. (2013). Young adult literature in the Malaysian secondary school. English Language Teaching, 6(11), 77-88.

Kalantzis, M., \& Cope, B. (2005). Learning by design. Melbourne: Victorian Schools Innovation Commission \& Common Ground.

Kaur, S., Ganapathy, M., \& Sidhu, G. K. (2012). Designing learning elements using the multiliteracies approach in an ESL writing classroom. The Southeast Asian Journal of English Language Studies, 18(3), 119-134.

Mills, K. A. (2006). Critical framing in a pedagogy of multiliteracies. In Proceedings Australian Literacy Educator's Association/Australian Association of the Teaching of English National Conference 2006: Voices, Vibes, Visions, Darwin.

Ministry of Education, Malaysia. (2009). Literature component for secondary schools: A collection of poems, short stories and drama Form 4 and 5. Kuala Lumpur: Perpustakaan Negara Malaysia.

Ministry of Education Malaysia. (2012). Preliminary report: Malaysia education blueprint 2013-2015. Putrajaya: Ministry of Education Malaysia.

Neville, M. (2010). Meaning making using new media: Learning by design case studies. E-Learning and Digital Media, 7(3), 237-247. Retrieved from http://newlearningonline.com/_uploads/5_Neville_ELEA_7_3_web.pdf 
New London Group. (2000). A pedagogy of multiliteracies: Designing social futures, in B. Cope \& M. Kalantzis (Eds) Multiliteracies: Literacy learning and the design of social futures, 9-38. South Yarra, Victoria: Macmillan.

Ntelioglou, B. Y., Fannin, J., Montanera, M., \& Cummins, J. (2014). A multilingual and multimodal approach to literacy teaching and learning in urban education: A collaborative inquiry project in an inner city elementary school. Frontiers in Psychology: Language Sciences, 5, 96-100.

Pandian, A. (2006). What works in the classroom? Promoting literacy practices in English. Southeast Asian Journal of English Language Studies, 11, 15-39.

Pantaleo, S. (2013). Revisiting Rosenblatt's aesthetic response through The Arrival. Australian Journal of Language and Literacy, 36(3), 125-134.

Rosenblatt, L. M. (1978). The reader, the text, the poem: The transactional theory of the literary work. Carbondale, IL: Southern Illinois University Press.

Rosenblatt, L. M. (2005). Making meaning with texts: Selected essays. Portsmouth, NH: Heinemann.

Sommers, J., Androne, H. A., Wahlrab, E., \& Polacheck, A. (2006). Critical reading outcomes and literary study in a problem-based learning (PBL) literature course. MountainRise, 3(1). Retrieved from http://mountainrise.wcu.edu/index.php/MtnRise/article/viewFile/86/55

Soter, A., Wilkinson, I., Connors, S., Murphy, K., \& Shen, V. (2010). Deconstructing 'aesthetic response' in smallgroup discussions about literature: A possible solution to the 'aesthetic response' dilemma. English Education, 42(2), 204225.

Tan, J. P., \& McWilliam, E. L. (2009). From literacy to multiliteracies: Diverse learners and pedagogical practice. Pedagogies: An International Journal, 4(3), 213-225.

Weiyun He, A. (2010). The heart of heritage: Sociocultural dimensions of heritage language learning. Annual Review of Applied Linguistics, 30, 66-82. 